\title{
Micro model analysis of JD6 and JD7 Eindhoven walls with fixed smeared crack model
}

\author{
Muhammet Karaton*iD, Kağan Çanakçı iD \\ Firat University, Engineering Faculty, Civil Engineering Department, Elazlğ, Turkey
}

\begin{abstract}
Micro, simplified micro and macro modelling are used for the numerical modeling of the masonry. In this study, the efficiency of a 3-dimensional fixed smeared crack model in the micro modelling of masonry walls is investigated. For this purpose, the experimental results of the masonry walls called as the JD6 and JD7 Eindhoven walls are selected. The concrete model with three parameters which special case of William Warnke model is used to calculate the nonlinear behavior of mortar and brick regions of this wall. Interface element is not use at between brick and mortar. Predictor-corrector technique used for nonlinear analysis. Numerical and experimental results are compared in terms of the base shear-peak displacement curve and the crack regions obtained in the walls. Good approximation are obtained between experimental and numerical results with regard to ultimate base-shear force obtained. Some differences are determined between experimental and numerical results with regard to threshold displacement value that calculated versus ultimate base-shear force.
\end{abstract}

\section{Keywords}

Masonry walls; Micro modelling; 3-dimensional fixed smeared crack; Eindhoven walls.

Received: 16 November 2019; Accepted: 03 March 2020

ISSN: 2630-5763 (online) C 2020 Golden Light Publishing All rights reserved.

\section{Introduction}

Masonry walls have been used for constructions of buildings since centuries. These constructional elements are still preferred. Nowadays, masonry walls are generally used in frame structure as filling material except from masonry building construction. It is known that these structural elements provide to positive contributions for earthquake resistance of buildings [1,2]. However, contributions of this element are not generally considered in numerical solutions of the buildings due to require complex analysis.

Three modelling techniques are suggested for analysis of masonry structure under static and seismic loadings in the literature [3-8]. These modeling techniques are Micro, Simplified micro and Macro modeling. Stone/brick and mortar materials are separately modeled in micro and simplified micro modeling techniques. In the macro modeling technique, stone/brick and mortar materials are homogenized as a continuum domain. Advantage of this technique, less element number according to micro and simplified micro modeling techniques in finite element model are used. Disadvantage of macro modeling technique, it cannot achieve ultimate load capacity and no damage zone geometry are accurately calculated. Large computational time and large computer

\footnotetext{
Corresponding author

Email: mkaraton@firat.edu.tr
} 
memory are required for numerical modelling of masonry buildings by using micro. Masonry walls with small scale can be only analyzed by these modelling techniques. Therefore, development of novel macro modelling techniques are required for accurately computation of load carrying capacity and damage zone geometry of masonry walls. Many researchers have focused on this problem and, have been developed simplified or alternative methodologies for reduce of computational effort in order to engineering practice [3-8]. In these researchers, Adam et al. [9] performed micromechanical modeling by a finite element method for a series of laboratory tests on masonry structures. Mortar and brick were modeled as solid material at the finite element model, and the interface of these two materials modeled with interface elements. The results of the non-linear numerical analysis and the experimental results were compared in terms of load-displacement and bending moment-rotation responses. Mohyeddin et al. [10] obtained analyses of reinforced concrete frames filled with masonry walls using threedimensional discrete finite elements. Ansys finite element program was used in the solutions. In order to validate this model, experimental data in the literature were used. It was observed that the model accurately reflected the effect on the fill frame inplane and out-of-plane loading cases. Caporale et al. [11] used the two-dimensional micro modelling to examine the effect of different masonry patterns and loading conditions on adobe walls. Experimental results showed that adobe bricks and mortars under compressive and tensile loads have different modulus of elasticity. Petracca et al. [12] presented a new damage mechanic model which based continuous domain for the analysis of masonry walls in micro scale. The model was compared with discrete micro modeling methods in the literature.

In this study, the efficiency of a 3-dimensional fixed smeared crack model in the micro analysis of masonry walls was investigated. A lot of researcher are often preferred for numerical modelling of the masonry walls. Therefore, effectiveness of the model should be investigate in micro modelling of the masonry wall. For this purpose, the experimental results of the masonry walls called as JD6 and JD7 Eindhoven walls were used. Numerical analyses were achieved by using Ansys finite element program [13]. William and Warnke model were selected for yield surface [14]. Numerical and experimental results were compared in terms of the base shear force-peak displacement curve and the crack regions obtained in the walls.

\section{Micro, simplified micro and macro modelling techniques for masonry walls}

Micro, simplified micro and macro scale modelling techniques are generally used for numerical analysis of masonry [4,15]. One of the finite elements, the discrete element or the finite volume element methods could be preferred for modelling. In the micro modelling technique, brick/stone and mortar are modelled by using different mechanical properties of material. Interface elements are used between these units. Finite element dimensions of brick/stone are extended to middle of mortar unit in the simplified micro modelling technique. In the macro modelling technique, brick/stone and mortar are homogenized by using composite material theories. Effective material properties equivalent to these materials are used (Fig. 1).

\section{William and Warnke model}

The model is called as three parameters model which a special case of five parameters model of William and Warnke [16]. Zeinkiewicz and Taylor [17] were stated that the model can be used for the brittle materials. This model is effectively used when macro modeling of the masonry structures $[9,10,17,18]$. This model is a similar to cone with convex cross-section as seen in Fig. 2.a [14]. In this figure, are principal stresses. $f_{c}$ and $f_{t}$ are uniaxial compressive and tensile strengths of the material, respectively. Softening behavior of the material under the tensile stress is given in Fig.2.b. In where, Tc is reduction coefficient of the tensile strength which after cracking initiation. $\varepsilon_{\mathrm{ck}}$ is threshold cracking strain and $6 \varepsilon_{\mathrm{ck}}$ is also taken for ultimate strain in the Ansys software. 


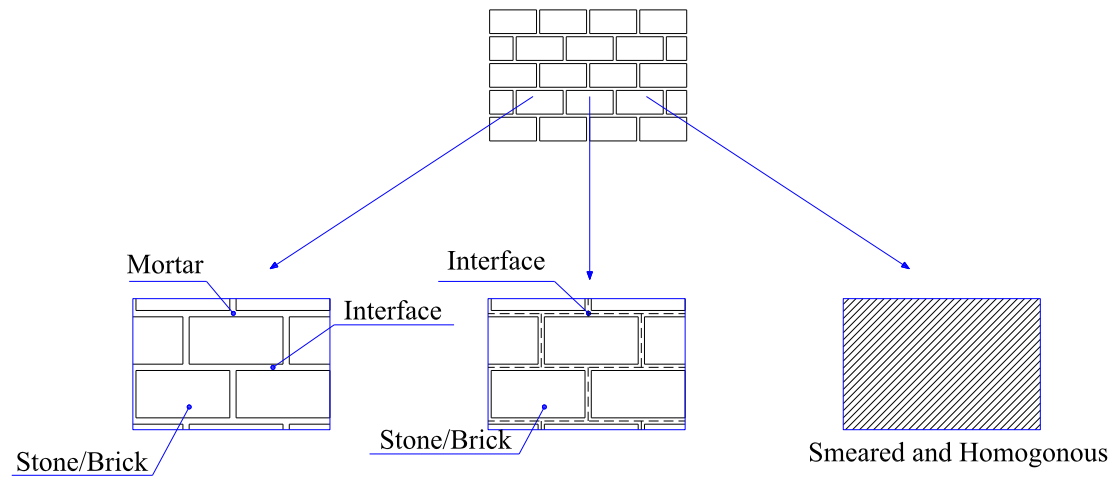

Fig. 1. Modelling techniques of masonry unit; a) micro, b) simplified micro and c) macro modelling $[4,15]$

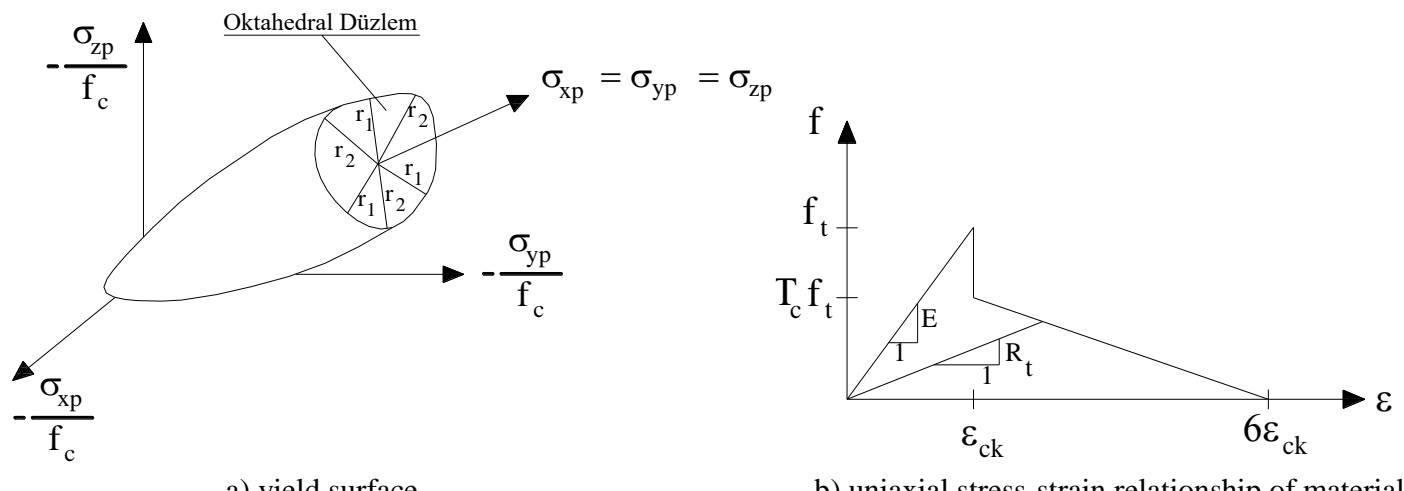

Fig. 2. Three parameters model [16].

\section{Micro model analysis of JD6 and JD7 walls}

In the numerical application, Eindhoven walls called as JD6 and JD7 were selected. Dimensions of JD4 wall are $990 \times 1000 \times 100 \mathrm{~mm}$. It was constructed by using brick with $210 \times 52 \times 100 \mathrm{~mm}$ dimensions and mortar with $10 \mathrm{~mm}$ thickness. Lower side surface of the wall was supported on the rigid surface. $120 \mathrm{kN}$ and $210 \mathrm{kN}$ preloading loads in vertical direction were applied to upper surface of JD6 and JD7 walls, respectively. Displacement controlled loading in the horizontal direction were applied at the upper side of walls as seen in Fig. 3 [20].

In this paper, experimental results of JD6 and JD7 walls were used for the numerical comparison. Numerical solutions of the two walls were obtained with "Micro modelling technique" by using finite element method. ANSYS finite element program was used for numerical analysis of the walls. Three dimensional solid concrete element of ANSYS (Solid 65) was selected. 33600 nodes and 21978 solid elements were used in finite element model in Micro Model of JD6 and JD7 walls (Fig.4). Interface element is not use at between brick and mortar. Boundary condition in direction of horizontal and vertical were applied to bottom of steel elements. Boundary conditions in direction of vertical were performed at upper side of top steel elements. In the solutions, self-weight for dead loading of walls and $120 \mathrm{kN}$ and $210 \mathrm{kN}$ for preloading were applied to wall in first loading stage. In second stage, loading based on displacement was applied to node in the upper side of the wall. Predictor-corrector technique used for nonlinear analysis. Material properties of brick and mortar used in the analyses were given in Table 1 and 2. $\mathrm{ft}$ and $\mathrm{fc}$ are shear retention factor in opening and closing case of a crack region, respectively. 


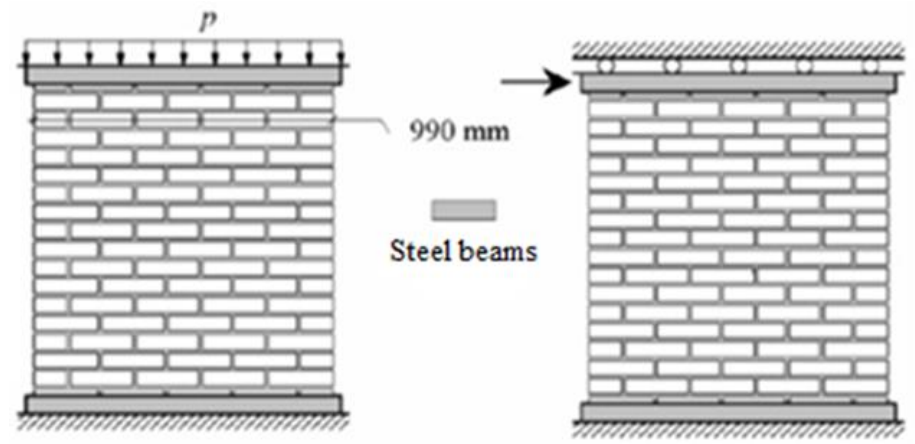

Fig. 3. Geometric properties, loading case and boundary conditions of JD6 and JD7 Eindhoven walls [20].

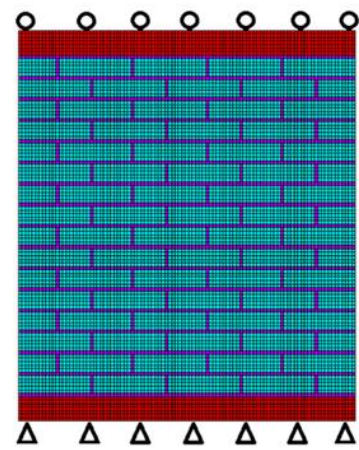

Fig. 4. Geometric properties, loading case and boundary conditions of JD6 and JD7 Eindhoven Wall.

Table 1. Material properties of JD6 wall

\begin{tabular}{cccccccc}
\hline Malerial type & $\mathrm{E}(\mathrm{MPa})$ & $v$ & $\rho\left(\mathrm{t} / \mathrm{m}^{3}\right)$ & $\mathrm{f}_{\mathrm{t}}(\mathrm{MPa})$ & $\mathrm{f}_{\mathrm{c}}(\mathrm{MPa})$ & $\beta_{\mathrm{t}}$ & $\beta_{\mathrm{c}}$ \\
\hline Brick & 9000 & 0.15 & 2.2 & 1.20 & 30.00 & 0.05 & 0.90 \\
Mortar & 2000 & 0.20 & 2.3 & 0.50 & 10.00 & 0.05 & 0.90 \\
\hline
\end{tabular}

Table 2. Material properties of JD7 wall

\begin{tabular}{cccccccc}
\hline Malerial type & $\mathrm{E}(\mathrm{MPa})$ & $v$ & $\rho\left(\mathrm{t} / \mathrm{m}^{3}\right)$ & $\mathrm{f}_{\mathrm{t}}(\mathrm{MPa})$ & $\mathrm{f}_{\mathrm{c}}(\mathrm{MPa})$ & $\beta_{\mathrm{t}}$ & $\beta_{\mathrm{c}}$ \\
\hline Brick & 16500 & 0.15 & 2.2 & 2.20 & 55.00 & 0.05 & 0.90 \\
Mortar & 2000 & 0.20 & 2.3 & 0.50 & 10.00 & 0.05 & 0.90 \\
\hline
\end{tabular}

Force-displacement graphs and fracture zones of the wall were obtained from nonlinear analyzes of the walls. Force-displacement graphs of the walls obtained from numerical analyses were compared with experimental results as seen in Fig. 5. Value of ultimate load capacity obtained from experimental test of JD6 wall was obtained as $74.87 \mathrm{kN}$. This value was calculated as $72.46 \mathrm{kN}$ (Fig.5.a) Thus, load capacity obtained from numerical solutions were computed as $3.32 \%$ smaller according to experimental test result. Value of ultimate load capacity obtained from experimental test of JD7 wall was obtained as $100.17 \mathrm{kN}$. This value was calculated as $99.62 \mathrm{kN}$ in the numerical analysis (Fig.5.b). Therefore, the load capacity obtained from numerical solutions were calculated as $0.55 \%$ smaller according to experimental test result. Threshold displacement values versus the ultimate load capacity of JD6 and JD7 walls were also determined as $1.22 \mathrm{~mm}$ and $1.56 \mathrm{~mm}$ from experimental results, respectively. 

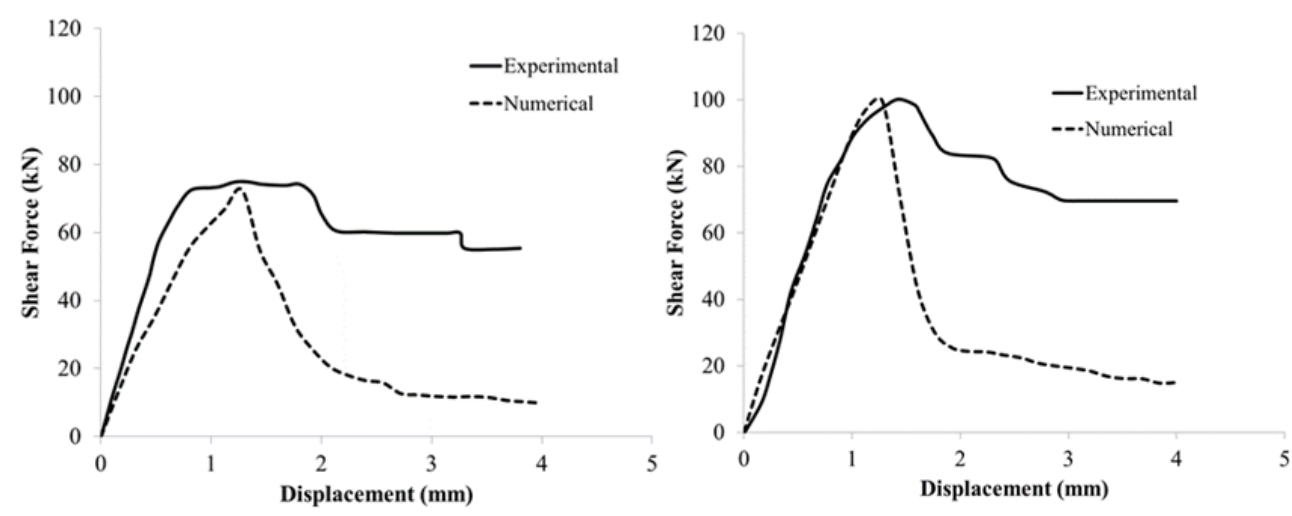

Fig. 5. Force-displacement graphs of JD6 and JD7 walls

The displacement versus the ultimate load capacity of both walls obtained from numerical solutions was $1.28 \mathrm{~mm}$. Differences between experimental and numerical displacement values for JD6 and JD7 walls were defined as $4.92 \%$ and $17.95 \%$, respectively. It is assumed that these differences are occurred due to boundary of softening region of the concrete model is fixed $\left(6 \varepsilon_{\mathrm{ck}}\right)$ and, due to uncertainty in shear stress calculating by reason of cracking effect in element.

Crack regions obtained from numerical (for different top displacement values) and experimental results of the JD6 and JD7 walls were given in Fig. 6 and 7. Crack regions of both walls were occurred 3 zones. First zone was started right top corner of the wall and extended to left side of the wall in the horizontal direction. Second zone was started left bottom corner of the wall and extended to right side of the wall in the horizontal direction. An additional cracking zone was also obtained between left top corner and right bottom corner as a diagonal form. Cracking zones obtained from experimental and numerical results are initially similar. But, in later loading phases, distributions were seem in cracking zones obtained from the numerical solutions.

\section{Results}

In this study, the efficiency of a 3-dimensional fixed smeared crack model in the micro analysis of masonry walls is investigated. For this purpose, the experimental results of the masonry walls called as the JD6 and JD7 Eindhoven walls are selected. In order to calculate the nonlinear behavior of the mortar and brick materials of this walls, fixed smeared crack model is used. Numerical and experimental results are compared in terms of the base shear force-peak displacement curves and the crack regions. Obtained results are given in following,

- Differences between experimental results and ultimate base-shear force obtained from numerical analysis of JD6 and JD7 walls are determined as $3.32 \%$ and $0.55 \%$ ratio, respectively.

- Differences between displacement values versus ultimate base-shear force obtained from numerical analyses of the JD6 and JD7 walls are determined as $4.92 \%$ and $17.95 \%$, respectively. It is assumed that these differences are occurred due to boundary of softening region of the concrete model is fixed (6 $\square \mathrm{ck})$. It should be changed according to finite element mesh size in the software.

- Crack regions of both walls are occurred 3 zones. First zone is started right top corner of the wall and extended to left side of the wall in the horizontal direction. Second zone is started left bottom corner of the wall and extended to right side of the wall in the horizontal direction. An additional cracking zone is also obtained between left top corner and right bottom corner as a diagonal form. Cracking zones obtained from experimental and numerical results are initially similar. But, in later loading phases, distributions were shown in cracking zones obtained from the numerical solutions. 


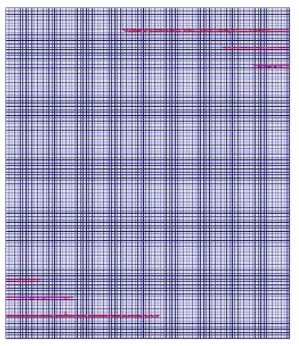

a) Numerical $\Delta \mathrm{x}=1.04 \mathrm{~mm}$

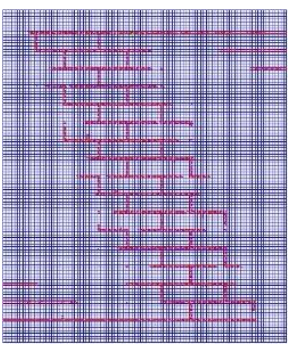

b) Numerical $\Delta \mathrm{X}=1.12 \mathrm{~mm}$

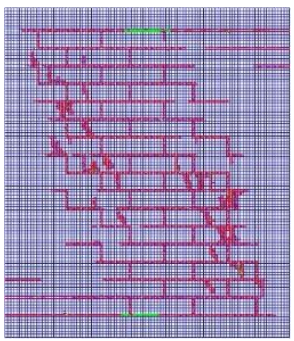

c) Numerical $\Delta \mathrm{x}=1.20 \mathrm{~mm}$

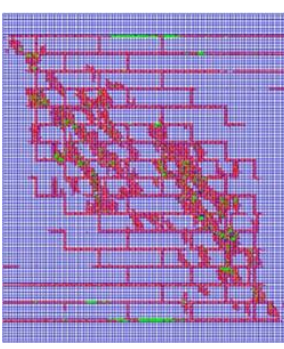

d) Numerical $\Delta \mathrm{X}=1.22 \mathrm{~mm}$

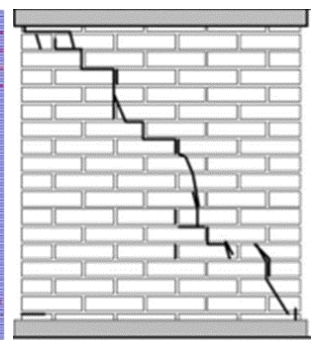

e) Experimental

Fig. 6. Crack regions of Eindhoven JD6 wall.

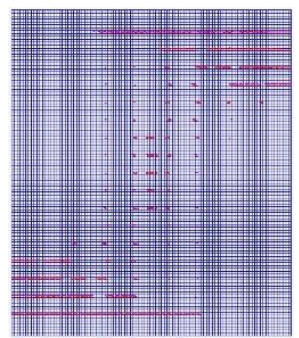

a) Numerical

$\Delta \mathrm{x}=1.04 \mathrm{~mm}$

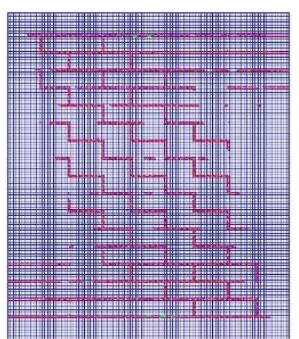

b) Numerical

$\Delta \mathrm{x}=1.08 \mathrm{~mm}$

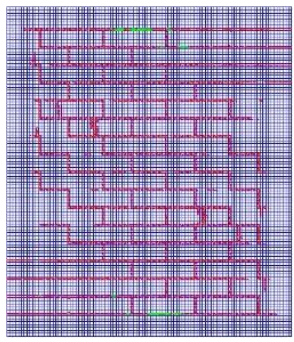

c) Numerical $\Delta \mathrm{x}=1.20 \mathrm{~mm}$

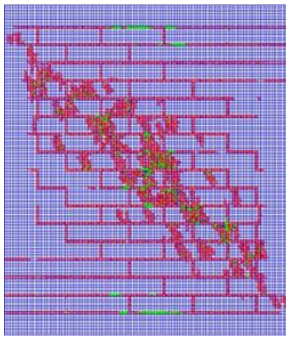

d) Numerical $\Delta \mathrm{x}=1.56 \mathrm{~mm}$

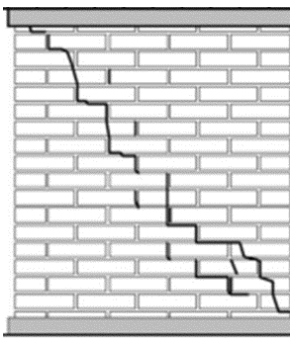

e) Experimental

Fig. 7. Crack regions of Eindhoven JD7 wall.

\section{Declaration of conflicting interests}

The author(s) declared no potential conflicts of interest with respect to the research, authorship, and/or publication of this article.

\section{References}

[1] Dilmac H, Ulutas H, Tekeli H, Demir F (2018) The investigation of seismic performance of existing RC buildings with and without infill walls. Computers and Concrete 22(5): 439-447.

[2] Kareem KM, Guneyisi EM (2019) Effect of masonry infill wall configuration and modelling approach on the behaviour of RC frame structures. Arabian Journal for Science and Engineering 44: 4309-4324.

[3] Chang X, Cheng X, Liu BW (2012) Modeling of influence of heterogeneity on mechanical performance. Construction and Building Materials 26: 90-95.

[4] Lourenço PB. Computational strategies for masonry structures. PhD Thesis. Delft University of Technology, Netherlands, 1996.

[5] Khattab MM, Drysdale RG. Nonlinear modelling of the shear response of grouted and reinforced concrete masonry. 10th International Brick/Block Masonry Conference, 5-7 July 1994, Calgary, Canada.

[6] Giambanco G, Rizzo S, Spallino R (2001) Numerical analysis of masonry structures via interface models. Computer Methods and Applied Mechanic in Engineering 190 (49-50): 494-511.

[7] Casolo S, Pena F (2007) Rigid element model for in-plane dynamics of masonry walls considering hysteretic behavior and damage. Earthquake Engineering and Structural Dynamics 36: 10291048.

[8] Chen SY, Moon, FL, Yi T (2008) A macro element for the nonlinear analysis of in-plane unreinforced masonry piers. Engineering Structures 30: 22422252.

[9] Adam JM, Brencich A, Hughes TG, Jefferson TT (2010) Micro-modelling of eccentrically loaded brickwork: Study of masonry wallets. Engineering Structures 32: 1244-1251.

[10] Mohyeddin A, Goldsworthy HM, Gad EF (2013) FE Modelling of RC frames with masonry infill panels under in-plane and out-of-plane loading. Engineering Structures 51: 73-87.

[11] Caporale A, Parisi F, Asprone D, Luciano R and Prota A (2013) Micromechanical analysis of adobe 
masonry as two-component composite: Influence of bond and loading schemes. Composite Structures 112: 254-263.

[12] Petracca M, Pelà L, Rossi R, Zaghi S, Camata G and Spacone E (2017) Micro-scale continuous and discrete numerical models for nonlinear analysis of masonry shear walls. Construction and Building Materials 149: 296-314.

[13] ANSYS. Analysis of Systems Finite Element Software, ANSYS Mechanical Academic Version, V16, 2016.

[14] Swanson Analysis System. ANSYS V16 Theory User's Manual, Chapter 8.1-8.5, 2015.

[15] Asan HN. Nonlinear analysis of masonry walls by using micro and macro modelling techniques. MSc Thesis. Firat University, Elazığ, Turkey, 2016 (in Turkish).
[16] William KJ, Warnke EP (1975) Constitutive model for the tri-axial behavior of concrete. Proceedings of the International Association for Bridge and Structural Engineering 19: 174-???.

[17] Zeinkiewicz OC, Taylor RL. Finite Element Method, Vol.2, McGraw-Hill, New York, USA, 1991.

[18] Cavicchi A, Gambarotta C (2005) Collapse analysis of masonry bridges taking into account arch fill interaction. Engineering Structures 27: 605-615.

[19] Chaimoon K, Attard, MM (2007) Modeling of unreinforced masonry walls under shear and compression. Engineering Structures 29: 20562068.

[20] Vermeltfoort AT, Raijmakers TM J. Deformation controlled tests in masonry shear walls. Part 2. Report No: TUE/BKO/93.08, Eindhoven University of Technology, Eindhoven, Netherlands, 1993 (in Dutch). 